\title{
P-194
}

\section{Flavonoids from Malaysian Uncaria Lanosa Var. Farrea}

\author{
Nursyaza Husna Shaharuddin ${ }^{1}$, Rohaya Ahmad ${ }^{1,2, *}$ and Nurhuda Manshoor ${ }^{2}$ \\ ${ }^{I}$ Faculty of Applied Sciences, Universiti Teknologi MARA, 40450 Shah Alam, Selangor, Malaysia; ${ }^{2}$ Atta-ur-Rahman \\ Institute for Natural Products Discovery, Universiti Teknologi MARA PuncakAlam, 42300 Bandar Puncak Alam \\ Selangor, Malaysia; E-mail: rohayaahmad@salam.uitm.edu.my
}

Uncaria species are generally used as spasmolytics, analgesics and sedatives for symptoms associated with nervous disorders but their primary uses derived from traditional medicine is for the treatment of hypertension. In Malaysia, Uncaria species is also known as "Gambir"/akar kait- kait or akar hitam and "gegambir paya" or "gegambir hitam" are recorded for Uncaria lanosa. Continuing our interest in the genus, phytochemistry of the stems of $U$. lanosa var. farrea has afforded three flavones, 3-methyl-3',4',5,7-tetrahydroxyflavone, quercetin, rutin and two coumarins, 4,7,8-trihydroxycoumarin and scopoletin along with two major alkaloids, pteropodine and isopteropodine. This is the first report of the isolation of 3-methyl-3',4',5,7tetrahydroxyflavone from a natural source. The structures of compounds were elucidated by various spectroscopic techniques including ${ }^{1} \mathrm{H},{ }^{13} \mathrm{C}$ and 2D NMR as well as by UV, IR and LC- MS methods and comparison with literature.

Keywords: Uncarialanosa var. farrea, 3-methyl-3',4',5,7-tetrahydroxyflavone, quercetin, rutin, 4,7,8-trihydroxycoumarin, scopoletin, pteropodine, isopteropodine. 